\title{
Solitary testicular neurofibromatosis with testicular abscess: a case report
}

\author{
Xiaodong Bian, Mancheng Xia, Hongjie Xie, Fan Cui, Jiawei Chen, Ruiqin Zhang, Weibing Shuang \\ First Clinical Medical College, Shanxi Medical University, Taiyuan 030001, China \\ Correspondence to: Weibing Shuang. First Clinical Medical College, Shanxi Medical University, Taiyuan 030001, China. Email: shuangweibing@126.com.
}

\begin{abstract}
Solitary neurofibroma of male reproductive system is a very rare benign peripheral nerve tumor. The literature data of 17 cases showed that most of the patients went to see a doctor because of the local painless enlargement of the reproductive system. We report a case of testicular neurofibromatosis diagnosed as enlargement of the scrotum and rupture of pus. After comprehensive consideration, the patients were given radical orchiectomy on the right side. This case report is helpful to the understanding of this rare tumor. Solitary neurofibromatosis of the reproductive system can also cause local infection and collapse, and we need to distinguish it from malignant tumors.
\end{abstract}

Keywords: Testicular neurofibromatosis; testicular abscess; testicular tumor; painless swelling; case report

Submitted Feb 07, 2020. Accepted for publication Mar 13, 2020.

doi: $10.21037 /$ tau.2020.03.26

View this article at: http://dx.doi.org/10.21037/tau.2020.03.26

\section{Introduction}

Neurofibromatosis (NF) is a genetic disease that leads to abnormal development of neural crest cells and may cause damages to multiple organ systems (1). Neurofibromas can occur in any part of the body, but they are rarely found in the reproductive system, with only 17 cases reported in the literature (2). Among them, only one case of neurofibroma originates in the testis (3). Patients with isolated neurofibromas in the reproductive system usually present with a local painless swelling as an initial symptom at the time of diagnosis. We report here the first case of a testicular solitary neurofibromatosis in a patient who presents with a localized testicular abscess. It is noted that the patient has a 21-year history of paraplegia.

\section{Case presentation}

The patient, a 43-year-old man, was admitted to the hospital because of the right-sided scrotal swelling for more than 30 days, which was accompanied by localized ulceration for 10 days. The swelling was about $6 \times 6 \times 7 \mathrm{~cm}^{3}$ in size and the patient denied any injury. Initially, the patient was diagnosed with testicular epididymitis in the outpatient clinic and treated with a continuous infusion of antibiotics for 20 days. However, the symptom did not improve, and the right scrotum continued to enlarge with the occurrence of local skin ulceration. Physical examination shows that the size of the right scrotum increased to be about $8 \times 8 \times 9 \mathrm{~cm}^{3}$, the scrotal skin was red, firm and swollen with rupture on the front of the scrotum and a little purulent discharge. A palpable mass of $5 \mathrm{~cm}$ in size was identified between the right testis and epididymis, which was adhered to adjacent tissue, with poor mobility. The transillumination test on the right scrotum was negative. The patient had a fracture of the T12 vertebral body due to a car accident 21 years ago, resulting in paraplegia below the level of the umbilicus. The patient has used the urinary catheter for a long time. The patient has no family history of neurofibromatosis. There were no abnormal laboratory testing results. The history of tuberculosis was denied and Mycobacterium tuberculosis was negative in secretion culture.

Table 1 shows the timeline of patient's diagnosis and treatment.

Figure 1 shows the magnetic resonance (MR) images of testis and epididymis. The right scrotum has short T1 signal intensity and slightly longer T2 signal intensity, in which multiple lines of long T1 and short T2 signal are found. The tumor with localized high signal intensity can 
Table 1 The timeline of patient's diagnosis and treatment

\begin{tabular}{llll}
\hline Timeline & Size $(\mathrm{cm}) /$ local symptoms and signs & Diagnosis & Treatment/curative effect \\
\hline-30 days & $6 \times 6 \times 7$, partial inflamed & Testicular epididymitis? & Ceftriaxone iv gtt, qd \\
-10 days & $\begin{array}{l}8 \times 8 \times 9, \text { partial inflamed with ulceration } \\
\text { and purulence }\end{array}$ & $\begin{array}{l}\text { Testicular epididymitis? Or testicular } \\
\text { tuberculosis? }\end{array}$ & Anti-infective for 20 days/ineffective \\
-5 days & $6 \times 6 \times 7$, interval's discharge pus & Suspected malignancy (MRI) & Ready for surgery \\
Operation & $6 \times 6 \times 7$, interval's discharge pus & Testicular neurofibromas (rapid pathological & Radical resection of right testis and \\
& & diagnosis) & right inguinal lymph node dissection \\
6 days & Postoperative changes, healing well & Testicular neurofibromas (histopathology) & Discharged \\
60 days & - & Satisfactory prognosis & \\
\hline
\end{tabular}

"-" means the time of before operation
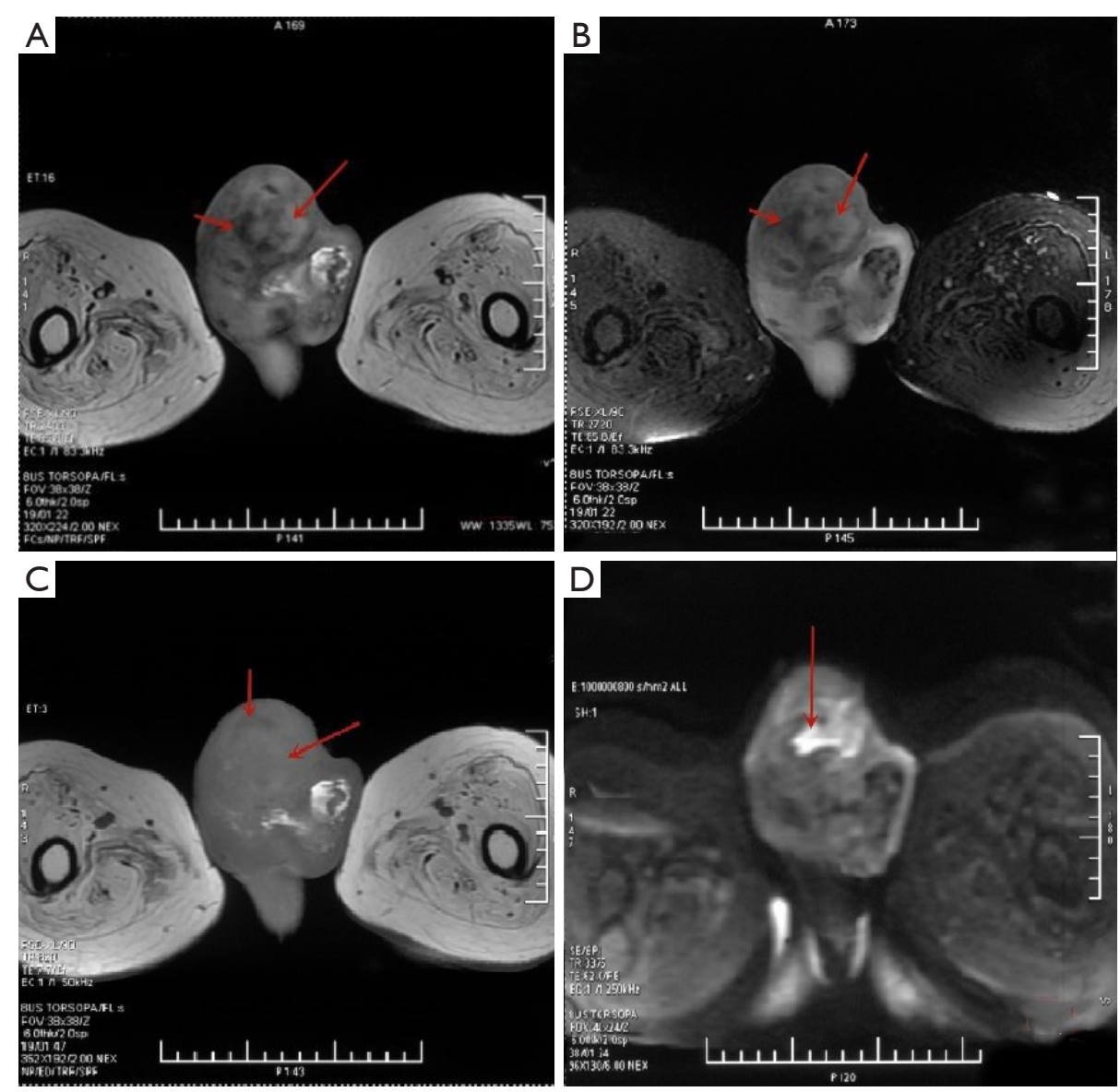

Figure 1 Testicular MRI shows that the abnormal structure of the testis and the presence of irregular masses of $5.1 \mathrm{~cm}$ in size in the testis and epididymis, indicating the possible formation of tumor-like tissue accompanied by infections. (A) T2-weighted image shows a large heterogeneous soft tissue mass (big arrow) containing several threadlike areas of low signal intensity (small arrow); (B) fat-suppressed T2weighted fast spin-echo sequence more clearly shows the contrast-enhanced T2-weighted signals, including low signal (small arrow) region and high signal area (big arrow) which are not affected by adipose tissue.; (C) T1-weighted image shows the presence of a heterogeneous soft tissue mass (big arrow) containing a linear region of low signal intensity (small arrow); (D) DWI image shows the localized high signal intensity within the right scrotum (arrow). 

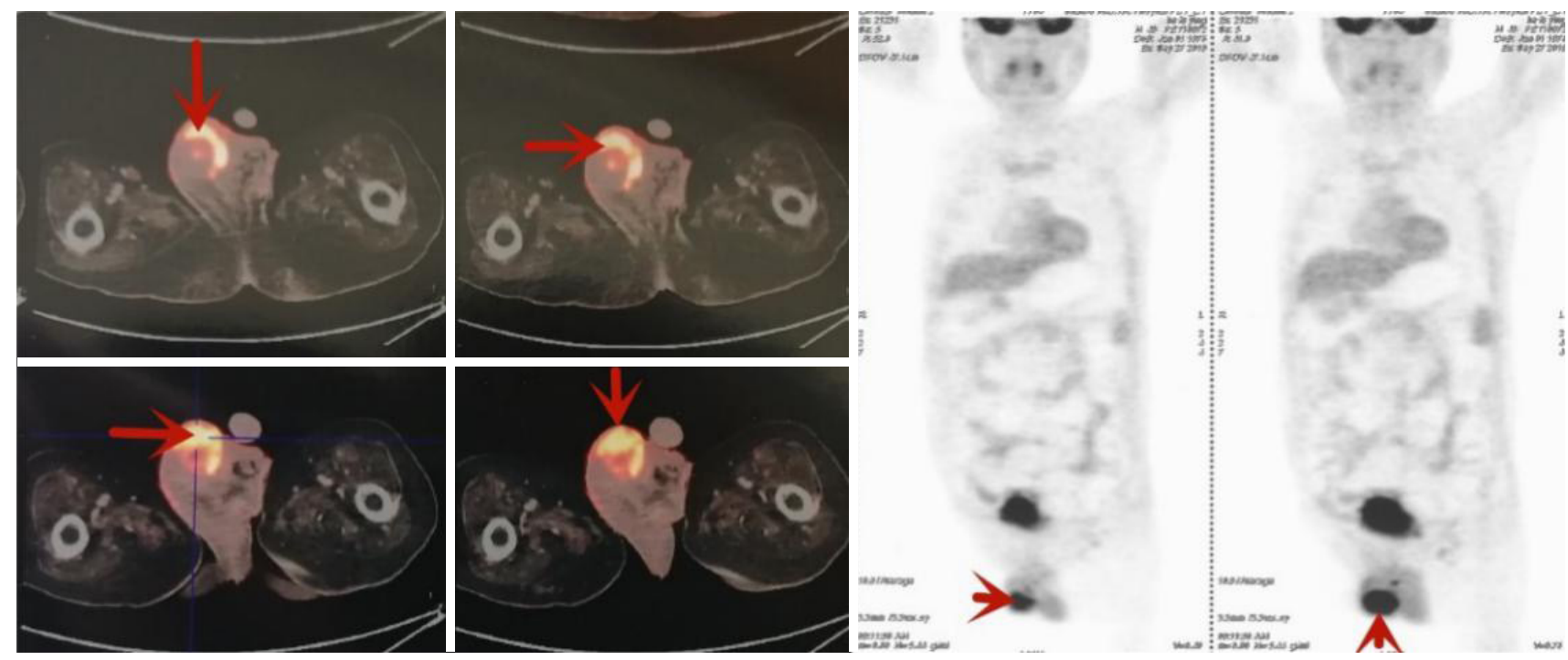

Figure 2 PET-CT showed a $5.1 \mathrm{~cm}$ irregular soft tissue mass in the right testis and epididymis (arrow).
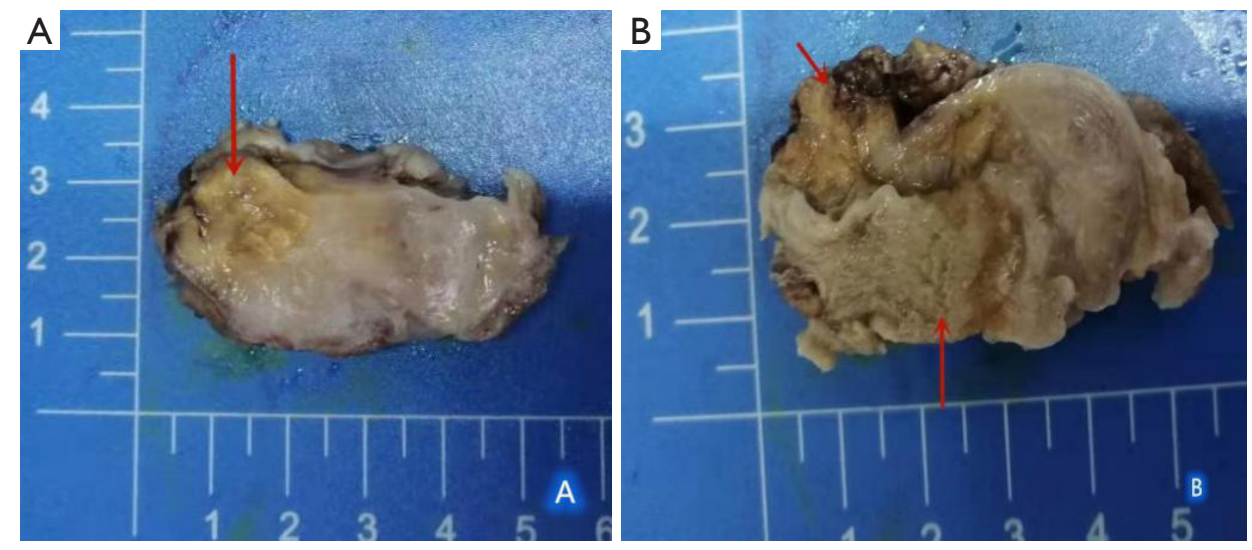

Figure 3 The macroscopic view of the surgical specimen showing the abnormal testis and epididymis and necrotic tissue. (A) Necrotic lesion in the testis (arrow) and (B) necrotic skin and internal tissue (small arrow) and unrecognized testicular tissue (big arrow).

be identified in DWI. The MR images show a structural abnormality (about $5.1 \mathrm{~cm}$ in size) in the right testis, a suggestive of a neoplastic lesion in the right scrotum accompanied by infections. As shown in Figure 2, PET-CT further confirms the presence of a heterogeneous soft tissue mass of $5.1 \mathrm{~cm}$ in the right testis and epididymis with the SUVmax of 13.15 and 21.69 at early and delayed scans, respectively, and bilateral lymph nodes in the inguinal lymph nodes of about $0.4-1.1 \mathrm{~cm}$ in size with the SUVmax of 1.652.01 and 3.1-7.17 at early and delayed scans, respectively.

The clinical manifestation of the patient suggests that the testicular mass may be malignant. Based on these results, the patient underwent radical right orchiectomy and right inguinal lymph node dissection. The intraoperative frozen section analysis suggests that the spindle cell tumor of the right testis is more likely to be neurofibroma. No tumor cells are found in the right spermatic cord, and the right inguinal lymph node shows reactive hyperplasia.

Figure 3 shows the abnormal morphology of testis and epididymis, as well as necrotic tissue in the testis. Histopathological examination shows the presence of spindle cells of neural origin in the testicular tissue (Figure 4).

Pathological results show that the testicular tumor is a benign neurofibroma. The patient was discharged and followed up within two months. The patient did not complain of any discomfort. 

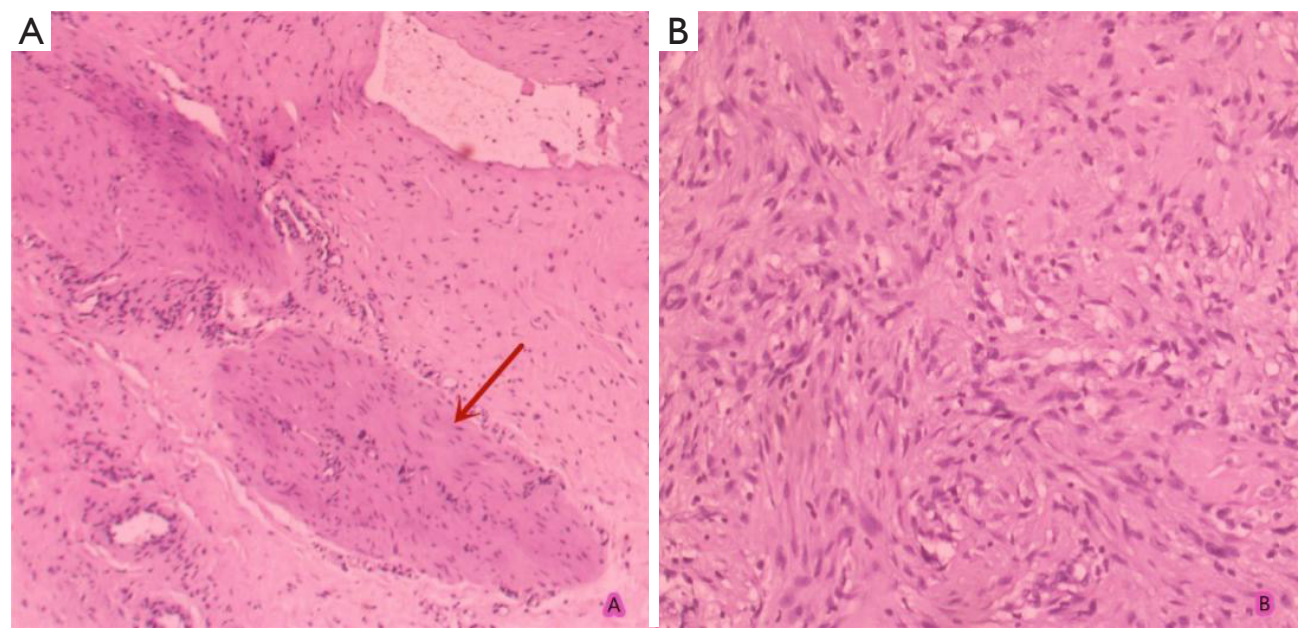

Figure 4 Histopathological evaluation of the specimen. (A) The appearance of neural tissue in the testicular tumor made up of spindle cells (arrow) (HE, $\times 100)$; (B) tumor cells arranged in bundles, the individual cells are uniform in size and not aggressive, with no cells in mitotic phase $(\mathrm{HE}, \times 200)$.

\section{Discussion}

Neurofibroma is a benign peripheral nerve tumor derived from the connective tissue sheath of the peripheral nerve, which often develops in the organs arising from the ectoderm, such as the nervous system, eye, and skin. NF is one of the common neurocutaneous syndromes (4). The neurofibromatosis often occurs synchronously in various tissues and organs of the body, and so far there are only about 17 cases of isolated neurofibromatosis in the reproductive system in the literature. Among them, the neurofibroma in 3 cases originates from the testicular tissue, including 1 case in the testicular tunica (5), 1 case in the testicular sheath (6), and 1 case in the testis (3).

There are two types of neurofibromatosis, including NF1 (type I) and NF2 (type II). NF1 has a variety of clinical manifestations, such as cutaneous and subcutaneous neurofibromas, Café-au-lait spots, freckles, and iris hamartoma (Lisch nodules). NF-2 mainly affects the central nervous system (nerves, meninges, spinal cord, etc.), and its clinical symptom is characterized by bilateral acoustic neuroma (7). We report the first case of isolated neurofibroma in the reproductive system with a testicular abscess as the initial symptom and without any abnormalities in other parts of the body. The main pathogenic mechanism for NF is solid stress from neurofibromas which compresses adjacent tissues surrounding the tumor. In our case, testicular neurofibroma likely compresses its adjacent normal tissues, resulting in necrosis and infection of the testicular tissue, followed by a persistent testicular abscess.

The probability that NF becomes malignant is very low. It is reported that even if the patient has systemic NF1 symptoms, the probability is only $4 \%$ (8). Those large, fast-growing tumors are more likely to develop into neurofibrosarcoma (9). In this case, the patient developed the symptoms of a testicular abscess, with the presence of enlarged lymph nodes in the inguinal region as shown in testicular MRI, which is easily misdiagnosed as a malignant tumor. It is worth noting that PET-CT plays a better guiding role than MRI in this case, and the reactive inflammatory changes of inguinal lymph nodes indicated by local metabolism are consistent with the pathological changes of reactive hyperplasia shown by postoperative pathological examination. Gupta et al. reported the first case of scrotal NF diagnosed by fine-needle aspiration cytology (10). This cytological examination can provide a more accurate preoperative diagnosis, which makes it possible to preserve the testis, which is of great significance to young patients. In summary, the final diagnosis of NF should be based on both cytological and pathological examination.

The most common clinical symptom of isolated neurofibromatosis in the reproductive system is a localized painless swelling. In order to relieve the symptoms of compression caused by the swelling and prevent malignant transformation, the patients are usually treated with complete tumor resection. It is also necessary to remove the genital organs when the tumor invades normal tissues and cannot be well segmented. In some cases where the 
tumor invades the testicle, orchiectomy is inevitable (11). Complete surgical resection of testicular neurofibromas can achieve a satisfactory outcome.

In conclusion, our research for this case has three strengths. First of all, testicular neurofibroma is rare, especially with a testicular abscess as the initial symptom, which has not been reported before. The case report can enrich doctors' understanding of it. Secondly, the case provides a new thinking of diagnosis and treatment for scrotal masses that show concomitant infection and ineffective antibiotic treatment. Third, PET-CT is highly sensitive to multiple inflammatory enlargement of lymph nodes and provides valuable help for clinicians in the diagnosis and treatment of similar diseases. However, our research has some limitations. Definite diagnosis of this disease mainly depends on histopathology. Although some studies had found that $50 \%$ of cases are spontaneous mutations (12), the patient rejected genetic testing. Therefore, we can only guess that the cause of the patient is genetic mutation.

\section{Acknowledgments}

$\mathrm{XB}$, WS and MX were in charge of the patient, recorded clinical information, and wrote the manuscript. RZ carried out histological examination. HX, JC and FC revised the paper and participated in critical discussion. All authors read and approved the final manuscript.

Funding: None.

\section{Footnote}

Conflicts of Interest: All authors have completed the ICMJE uniform disclosure form (available at http://dx.doi. org/10.21037/tau.2020.03.26). The authors have no conflicts interest to declare.

Ethical Statement: The authors are accountable for all aspects of the work in ensuring that questions related to the accuracy or integrity of any part of the work are appropriately investigated and resolved. Informed consent for the publication of the report, and the accompanying images, was provided by the patient's next of kin. The submission version of the report was read by the next of kin, and the report's content was confirmed as being correct to the best of her knowledge.

Open Access Statement: This is an Open Access article distributed in accordance with the Creative Commons Attribution-NonCommercial-NoDerivs 4.0 International License (CC BY-NC-ND 4.0), which permits the noncommercial replication and distribution of the article with the strict proviso that no changes or edits are made and the original work is properly cited (including links to both the formal publication through the relevant DOI and the license). See: https://creativecommons.org/licenses/by-ncnd/4.0/.

\section{References}

1. He XL, Hu TH, Guan YZ. A case of neurofibromatosis type I with malignant transformation. Chinese Journal of Surgical Oncology 2013;5:264-5, 268.

2. Zhang LM, Zheng P, Miao YL, et al. A case report of neurofibroma in the scrotum and literature review. Chinese Journal of Andrology 2018;24:1053-5.

3. Livolsi VA, Schiff M. Myxoid Neurofibroma of the Testis. J Urol 1977;118:341-2.

4. Hong $\mathrm{W}$, Li YJ, Jia ZL. Clinical analysis of 24 cases of neurofibromatosis. Modern Oncology 2012;(7):1447-50.

5. Pinilla I, Reinoso J, González-Peramato P, et al. Testicular albuginea neurofibroma: findings at ultrasonography and magnetic resonance imaging with pathological correlation. Arch Esp Urol 2009;62:498-501.

6. Tian HX. Testicular sheath neurofibroma: case report. Journal of Clinical Urology 2011;26:803.

7. Wang YB, Huang SZ. Molecular biological characteristics and diagnosis and treatment of neurofibromatosis. Chinese Medical Aesthetics and Beauty Magazine 14:283-4.

8. Stoller DW, Tirman PF, Bredella MA. Diagnostic imaging, or-thopaedics. British J Sports Med 2004;40:373.

9. Song YD, Ma ZP. A case of malignant scrotal neurofibroma. Chinese Journal of Gerontology 2014;34:6491-2.

10. Gupta S, Gupta R, Singh S, et al. Solitary intrascrotal neurofibroma: A case diagnosed on aspiration cytology. Diagnostic Cytopathology 2011;39:843-6.

11. Schulte TL, McDonald JR, Priestley JT: Tumors of the spermatic cord: Report of a case of neurofibroma. J Am Med Assoc 1939;112:2405.

12. Lang XQ, Sun YH, Fu XA, et al. Mutation analysis in three cases with sporadic neurofibromatosis type 1. China Journal of Leprosy and Skin Diseases 2019;35:9-12.

Cite this article as: Bian X, Xia M, Xie H, Cui F, Chen J, Zhang R, Shuang W. Solitary testicular neurofibromatosis with testicular abscess: a case report. Transl Androl Urol 2020;9(3):1437-1441. doi:10.21037/tau.2020.03.26 